\title{
Citações do Antigo Presidente do Conselho de Ministros Traduzidas para Um Crioulo Pessoal 2020
}

\section{Irineu Destourelles}

www.irineudestourelles.com

- mail@irineudestourelles.com

DoI https://doi.org/10.34913/

journals/lingualugar.2020.e425
As sete citações encontram-se dispersas ao longo da presente revista, nas páginas 4,12 , $122,142,154,172$ e 184.

Les sept citations sont réparties dans la présente revue, aux pages $4,12,122,142,154$, 172 et 184. 
Em 2011, então a viver e a trabalhar na ilha de São Vicente em Cabo Verde, fiz uma viagem ao interior da ilha de Santo Antão para visitar a casa dos avós de um amigo meu para ver o que restava da coleção de livros que o seu falecido avô tinha acumulado maioritariamente durante o regime Salazarista do Estado Novo Português. O texto, traduções 'no meu' crioulo diasporizado de citações de Salazar sobejamente conhecidas, sobrepõem-se a imagens provenientes de fotografias que tirei dentro e ao redor da casa durante a minha estadia. Pergunto-me até que ponto vivem no lugar remoto da ex-colônia detalhes da doutrina.

(O meu amigo disse-me que o seu avô, professor primário de profissão numa uma zona rural no interior da ilha de Santo Antão e amigo de escritores Cabo-verdianos do movimento modernista literário Claridade (f. 1936), tinha sido um ávido leitor encomendando livros regularmente de uma livraria em Lisboa. O movimento Claridade emerge como uma tentativa de criar uma escrita que refletisse a cultura crioula das ilhas de Cabo Verde. O seu avô foi amigo de Manuel Lopes, um dos fundadores do movimento Claridade que por altura da Segunda Guerra Mundial e durante alguns anos viveu no interior da ilha de Santo Antão. Fiquei curioso por saber que tipo de livros ele teria escolhido ler, dentro do que teria sido permitido pela censura do regime. Perguntava-me que conceitos para além da matriz cultural local teriam construído o universo do avô do meu amigo enquanto procurava manifestações desses conceitos na sua vivência através do que diziam dele. Disseram-me que com o tempo foi-se desligando da convivência com a comunidade e a família prezando o silêncio e a solidão.) 
146 En 2011, vivant et travaillant alors sur l'île de São Vicente au Cap-Vert, j'ai fait un voyage à l'intérieur de l'île de Santo Antão pour visiter la maison des grands-parents de l'un de mes amis afin de voir ce qui restait de la collection de livres que son défunt grand-père avait accumulée principalement sous le régime de Salazar et de l'Estado Novo portugais. Le texte, des traductions "dans mon propre" créole diasporique de citations bien connues de Salazar, se superposent à des images provenant de photographies que j'ai prises dans et autour de la maison pendant mon séjour. Je me demande dans quelle mesure des détails de la doctrine vivent dans cet endroit éloigné de l'ancienne colonie.

(Mon ami m'a raconté que son grand-père, instituteur de profession dans une zone rurale de l'intérieur de l'île de Santo Antão et ami d'écrivains capverdiens du mouvement littéraire moderniste Claridade (fondé en 1936), avait été un lecteur avide qui commandait régulièrement des livres dans une librairie de Lisbonne. Le mouvement Claridade est apparu comme une tentative de créer une écriture qui reflète la culture créole des îles du Cap-Vert. Son grand-père était un ami de Manuel Lopes, l'un des fondateurs du mouvement Claridade qui, pendant quelques années au moment de la Seconde Guerre mondiale, a vécu à l'intérieur de l'île de Santo Antão. J'étais curieux de savoir quel genre de livres il avait choisi de lire, dans le cadre de ce qui aurait été autorisé par la censure du régime. Je me suis demandé quels concepts, au-delà de la matrice culturelle locale, auraient construit l'univers du grand-père de mon ami, tandis que je cherchais des manifestations de ces concepts dans son expérience à travers ce qu'ils me disaient de lui. Ils m'ont dit qu'au fil du temps, il s'est déconnecté de la communauté et de la famille, cherchant le silence et la solitude.) 


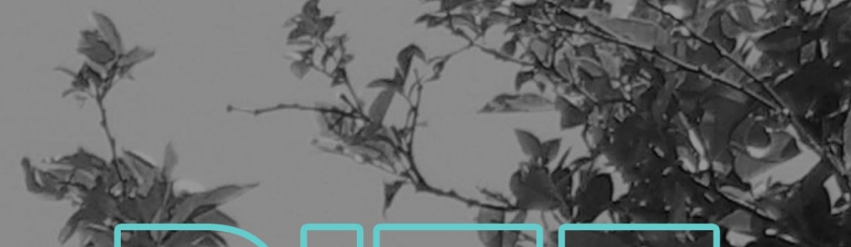

\section{$\triangle 1$ ह \\ . \\ 2) 1300 \\ 2)} ato

\section{I}

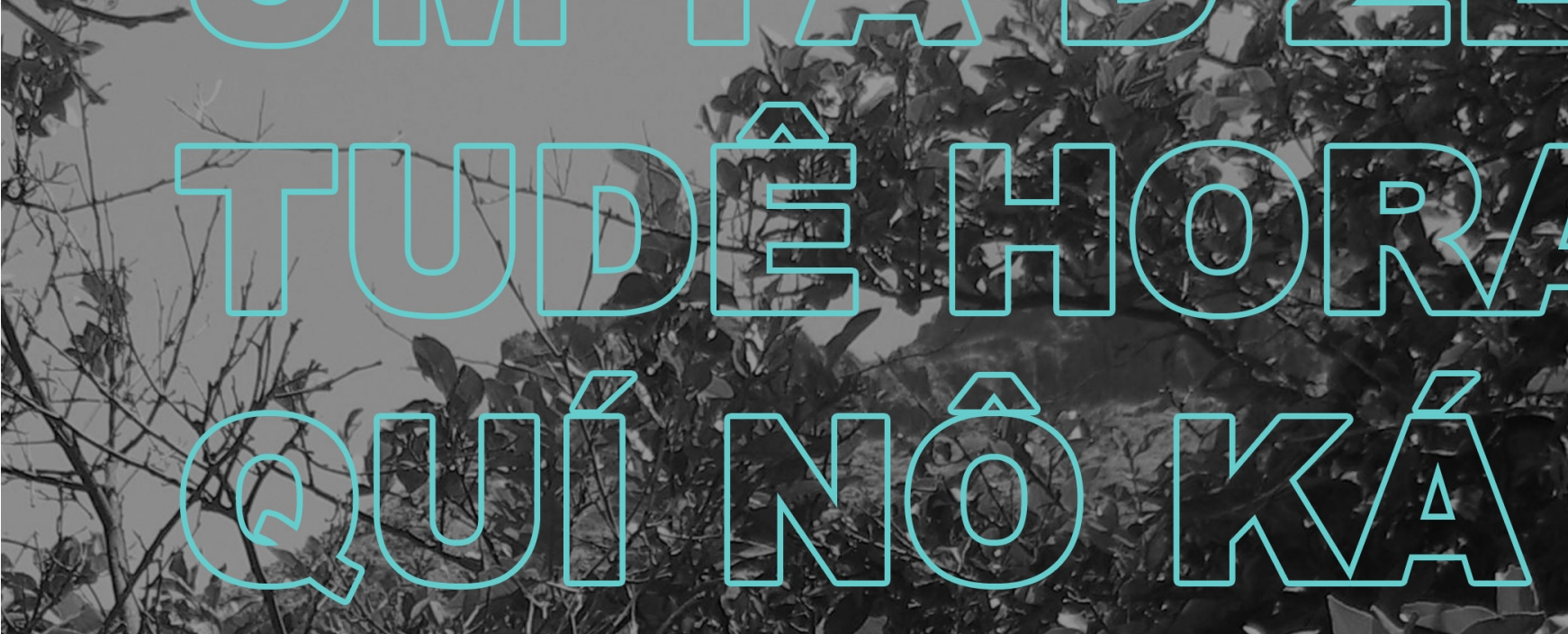

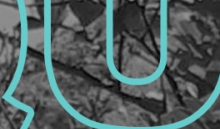

64 anch

\section{-}

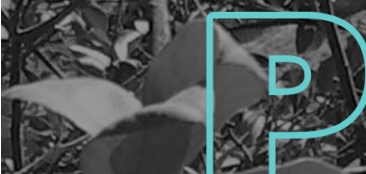

12.

(2). D. $\sqrt{1}$

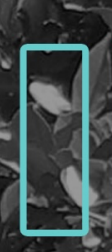

(3)

c

12.

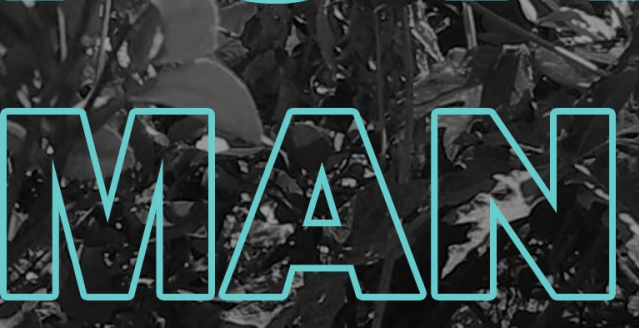

iti

का

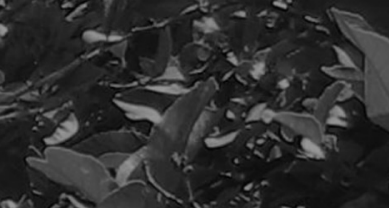

in

20
3

\section{.}
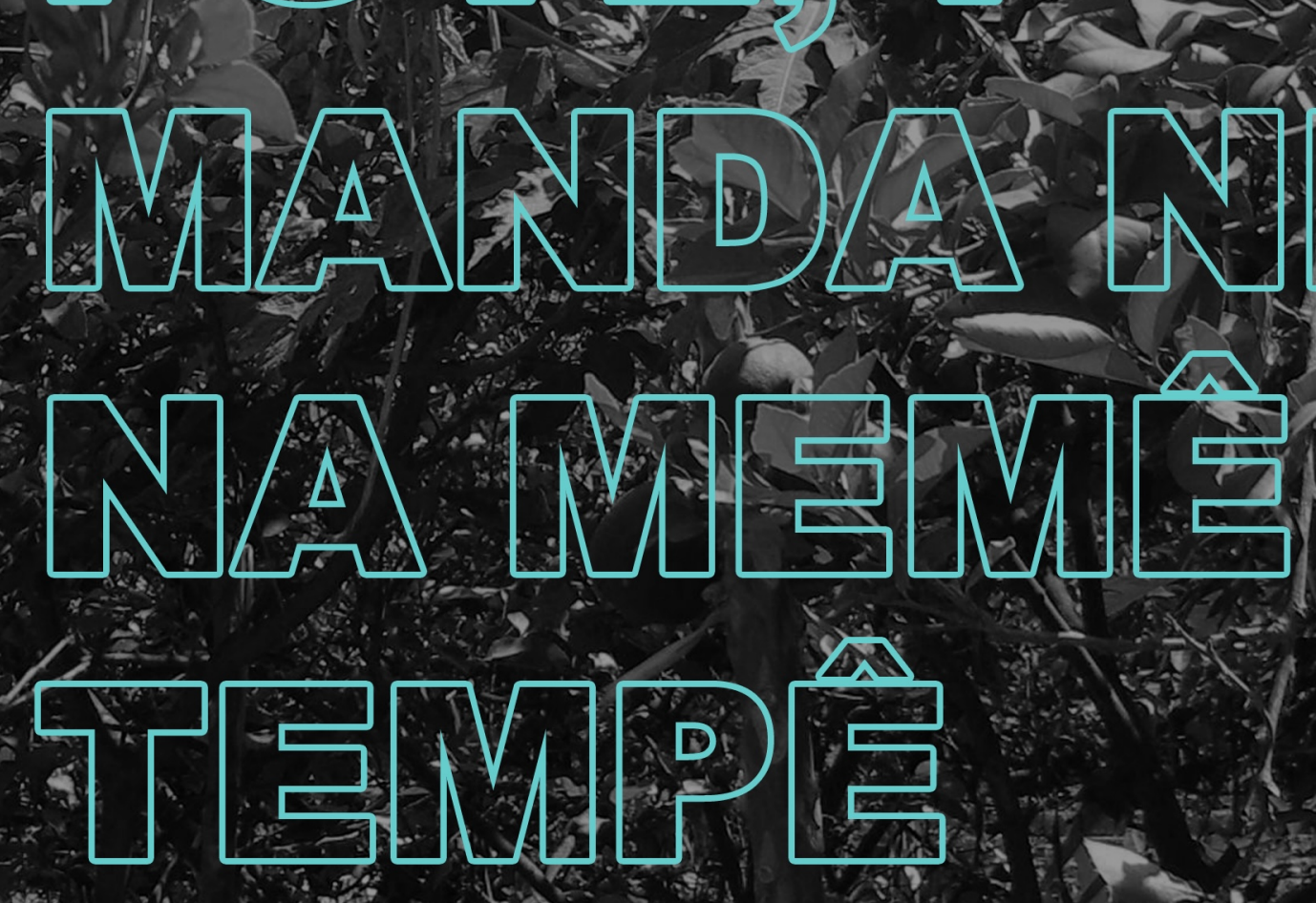


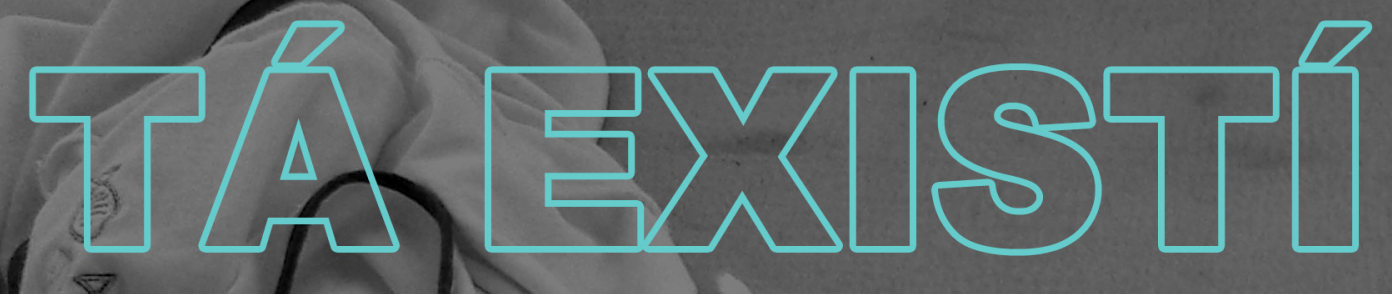

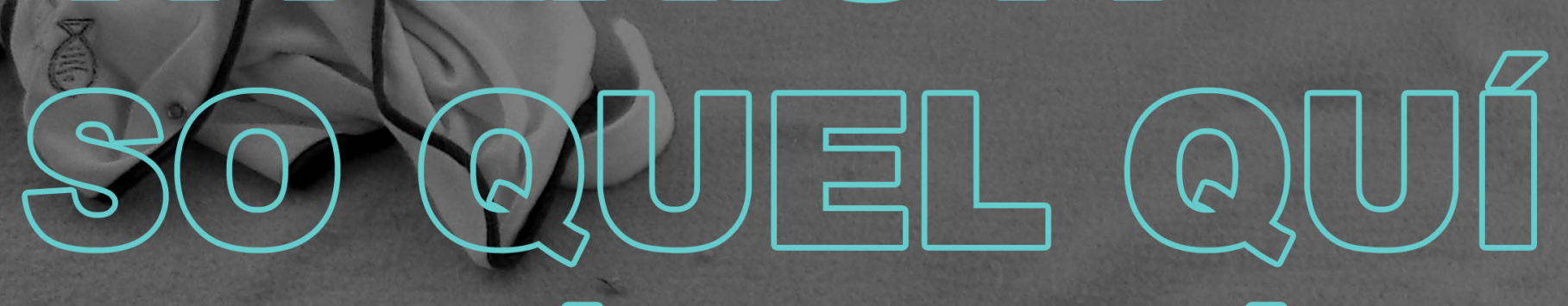

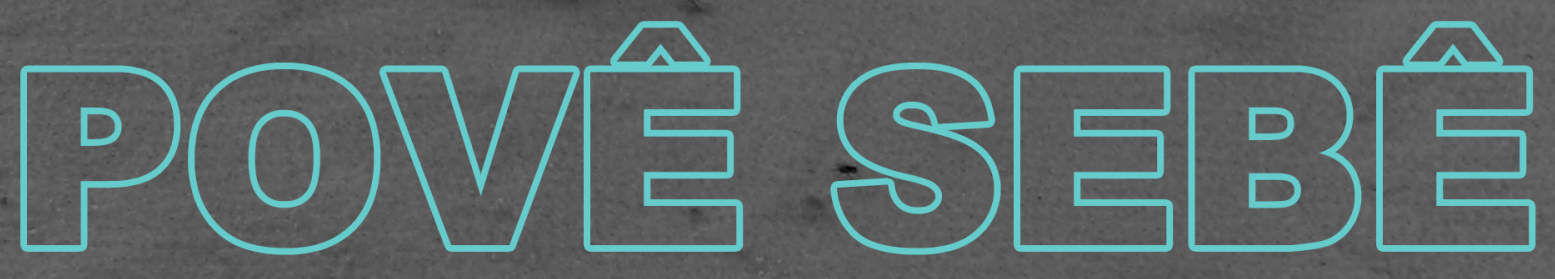

(A) UR एक

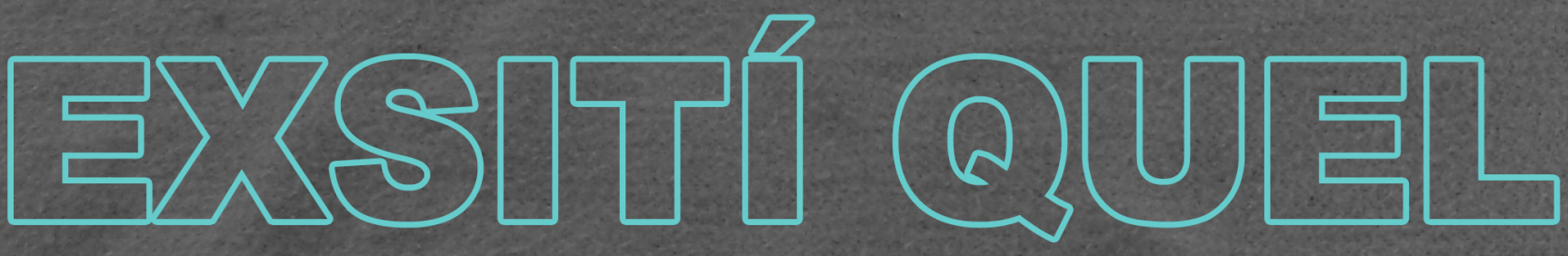

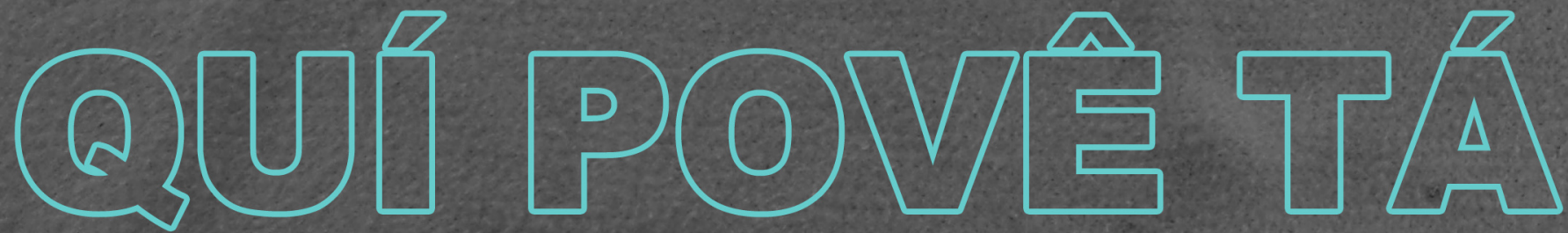

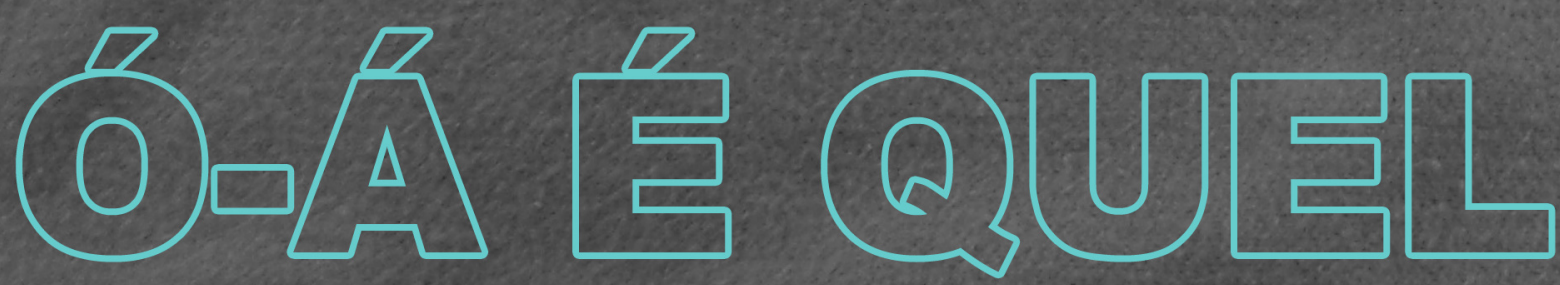

(A) आ 


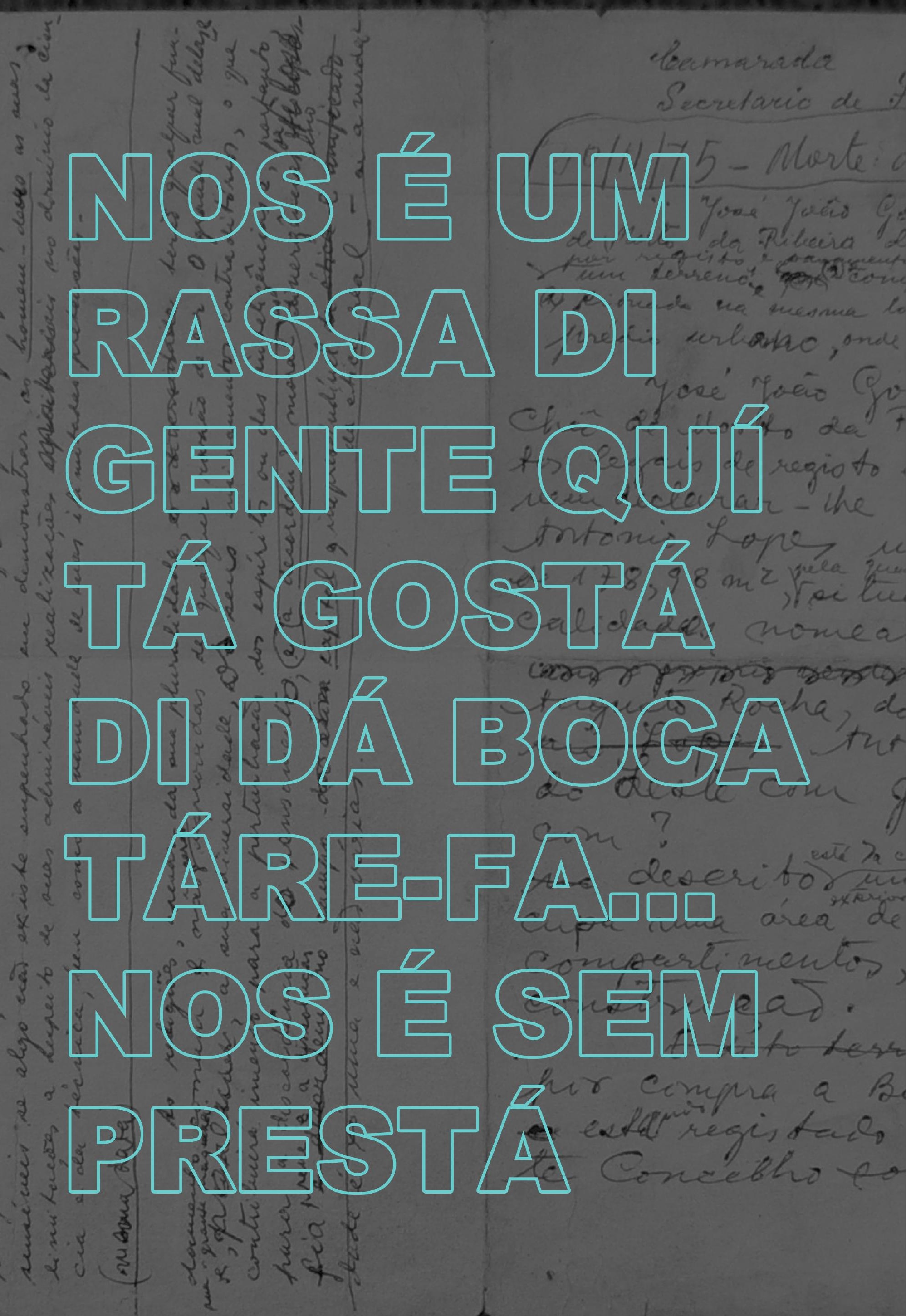


N(0) T绾W
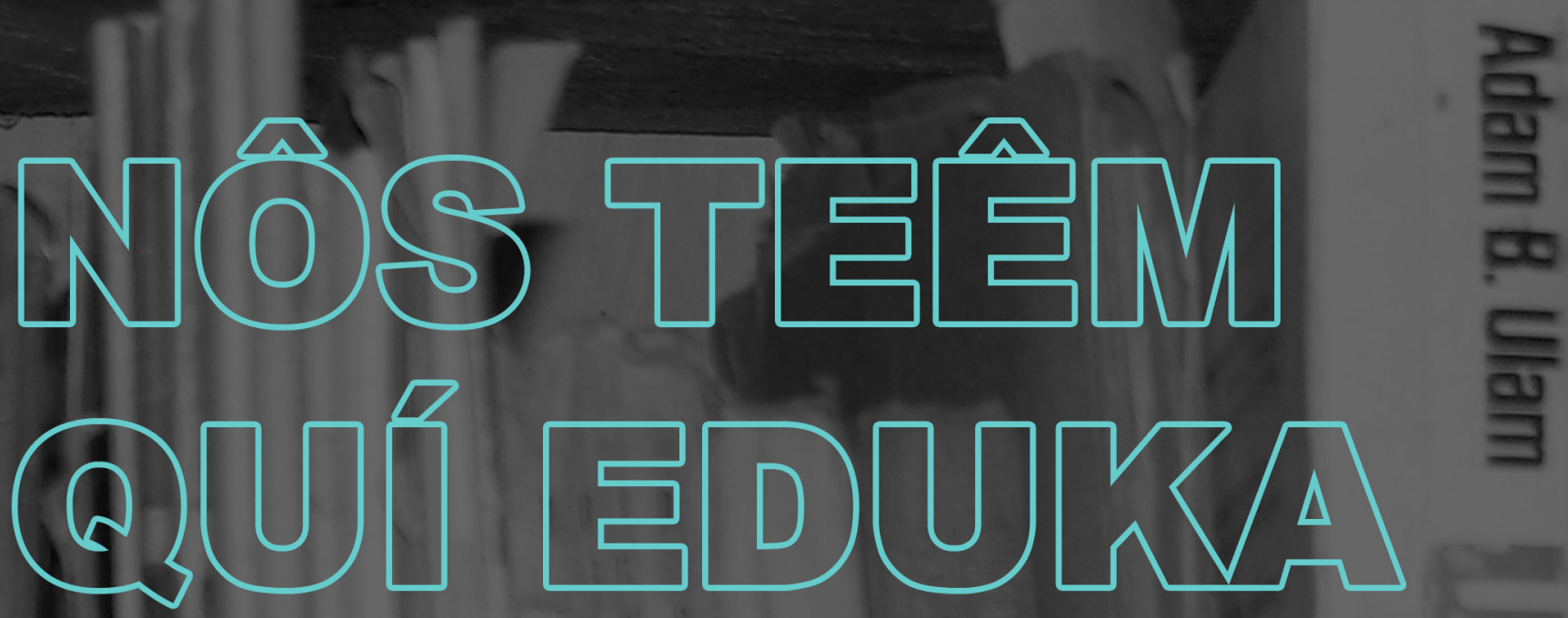

要88

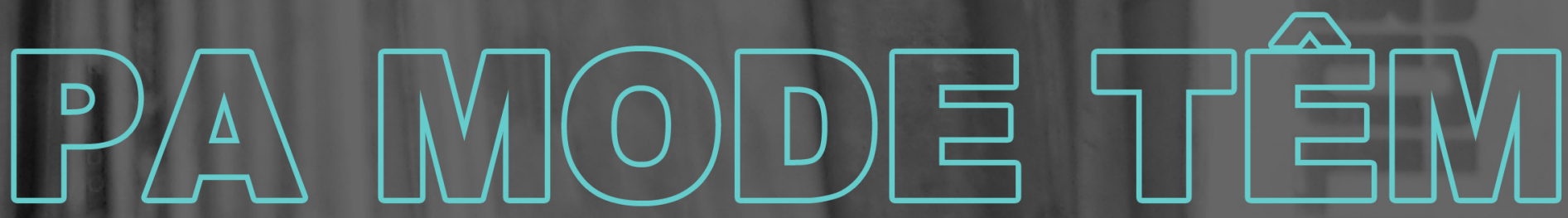

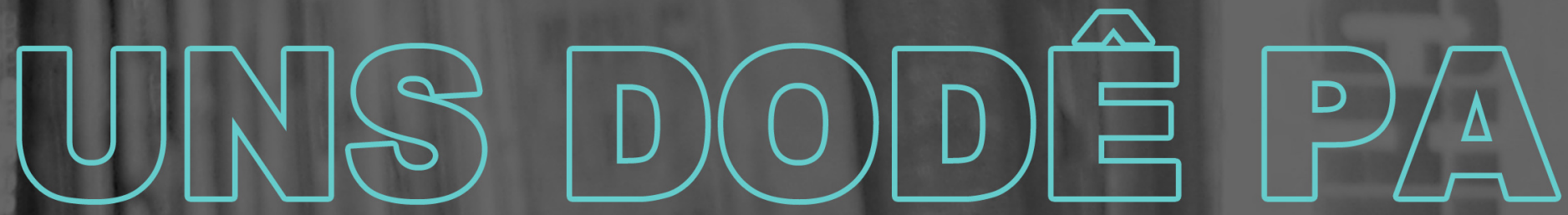

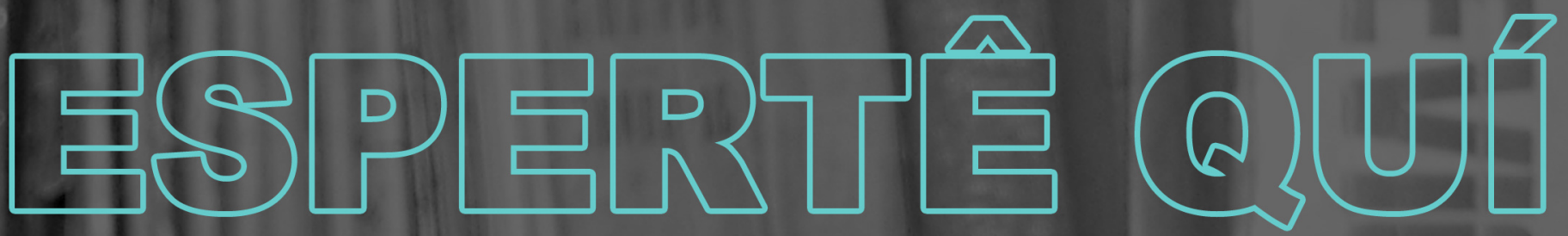

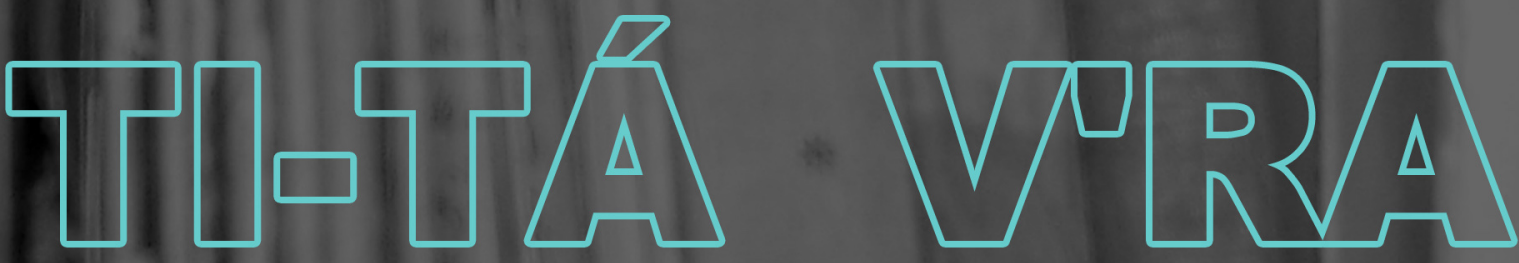

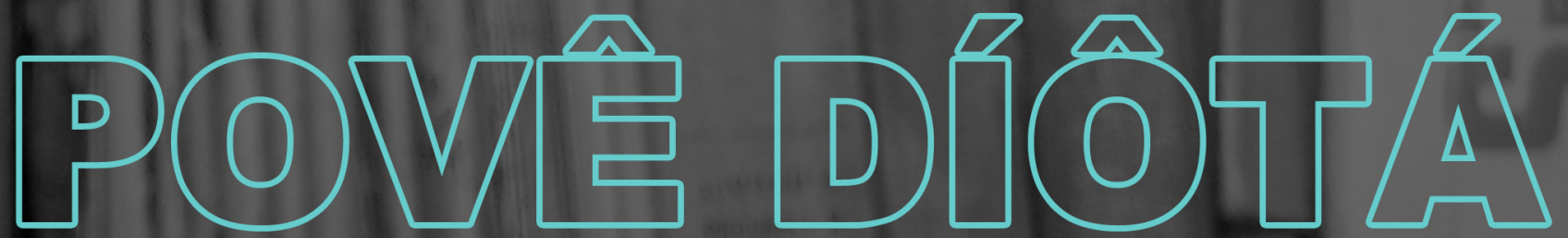




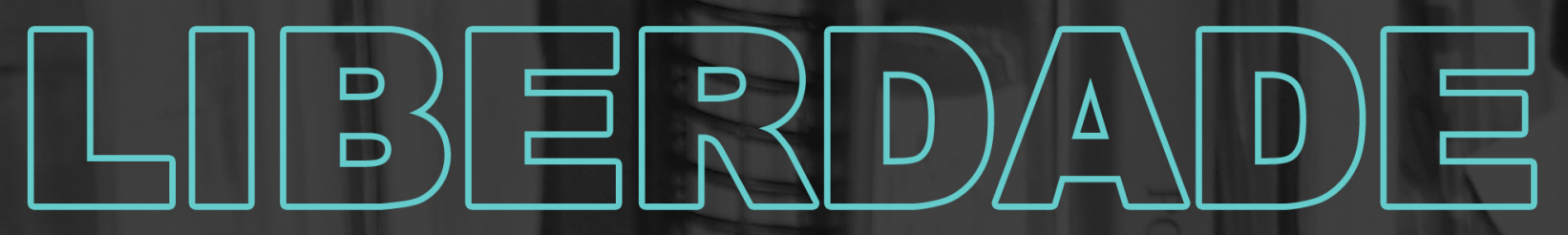

(8)
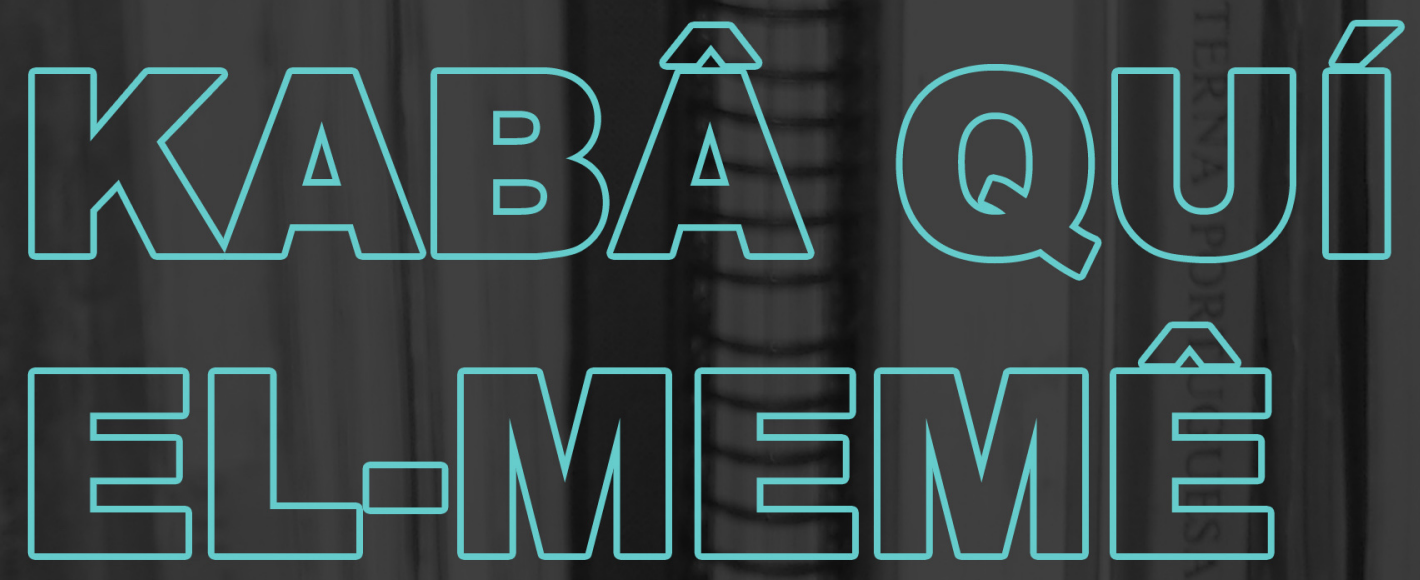

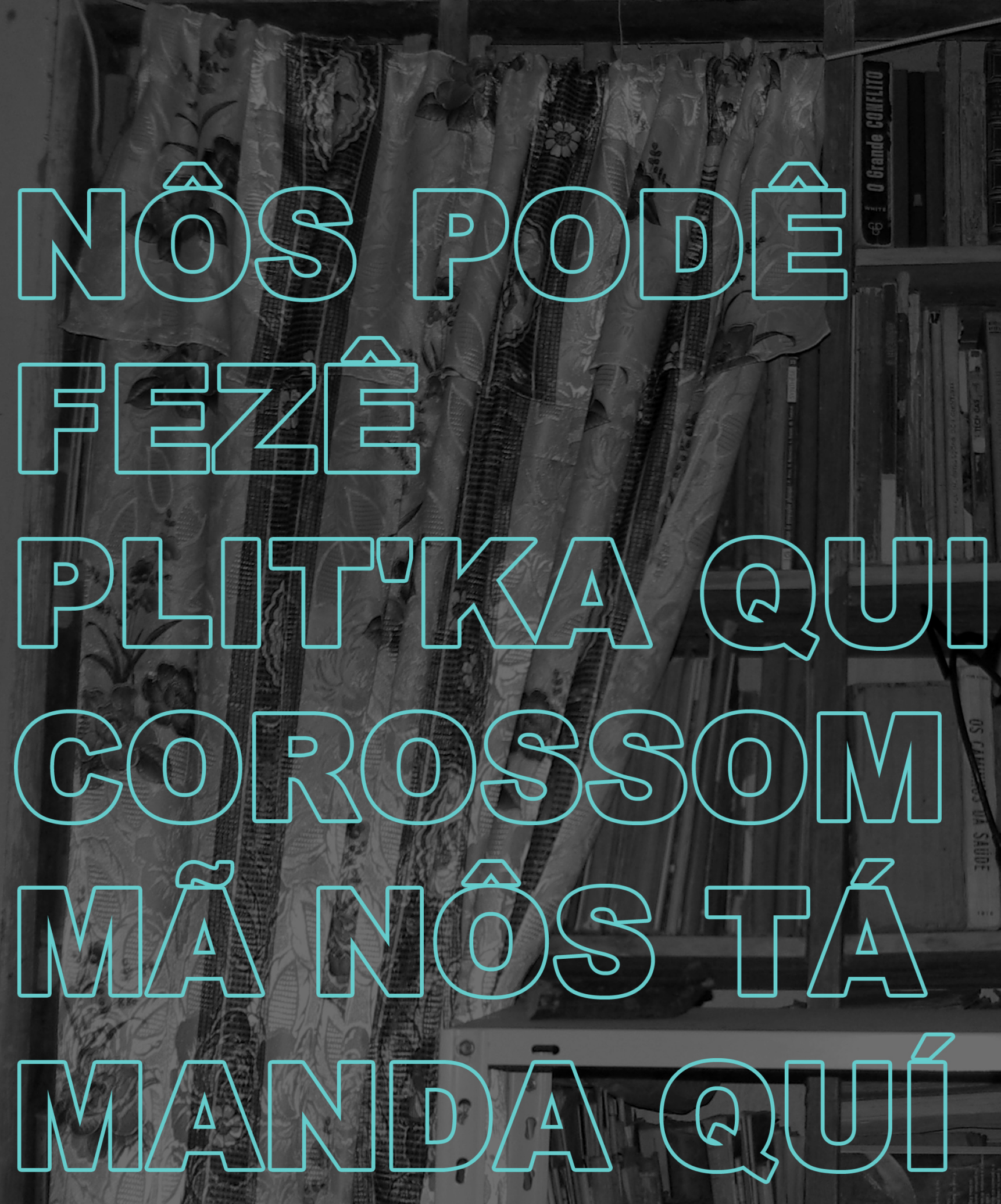

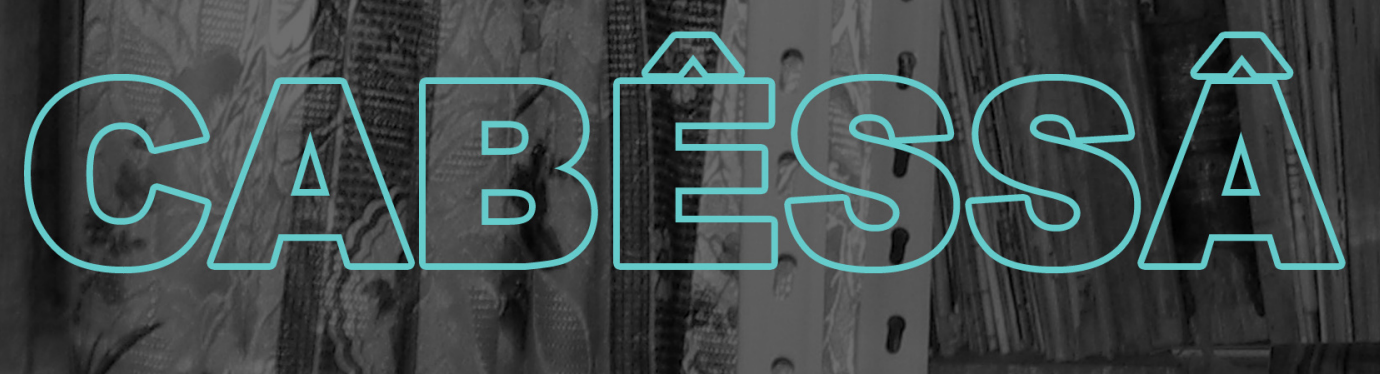




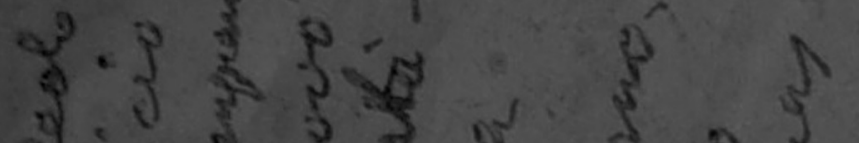

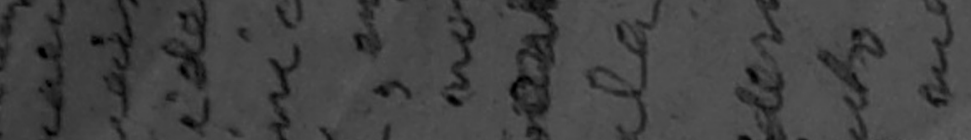

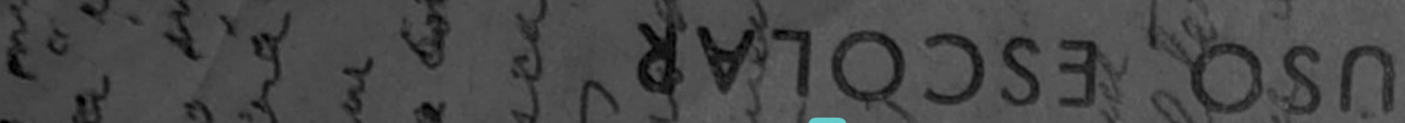

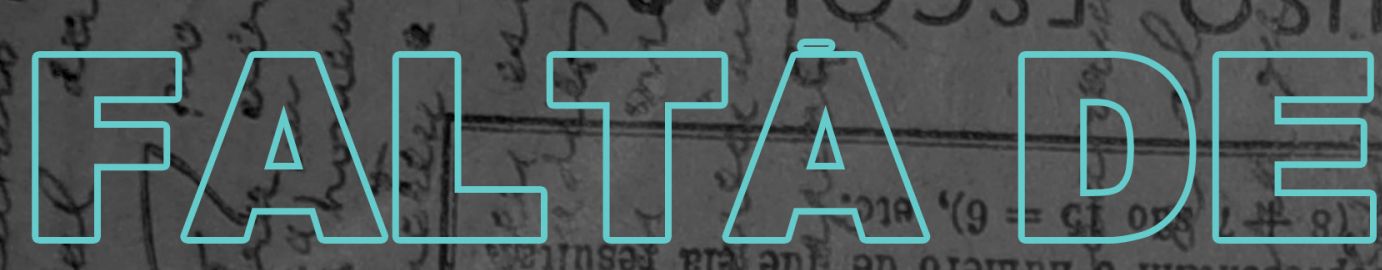

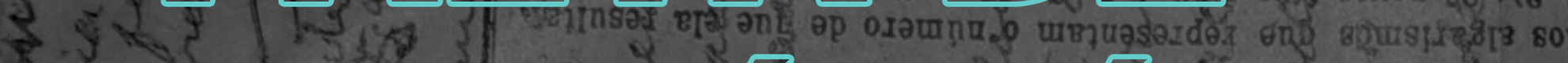
(1)

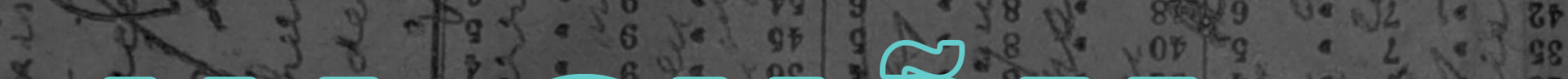

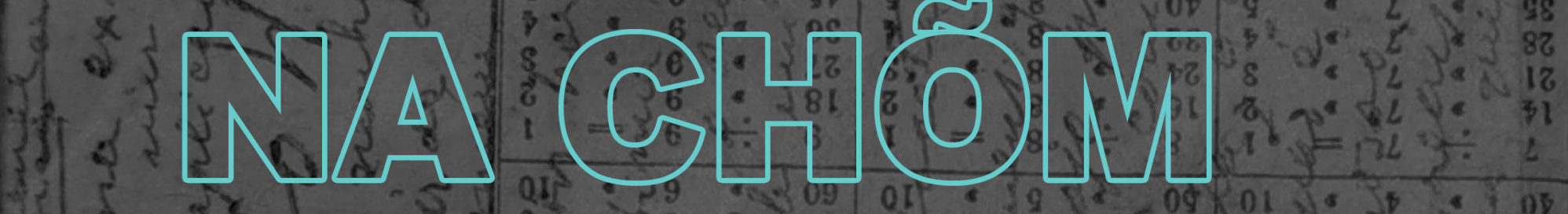
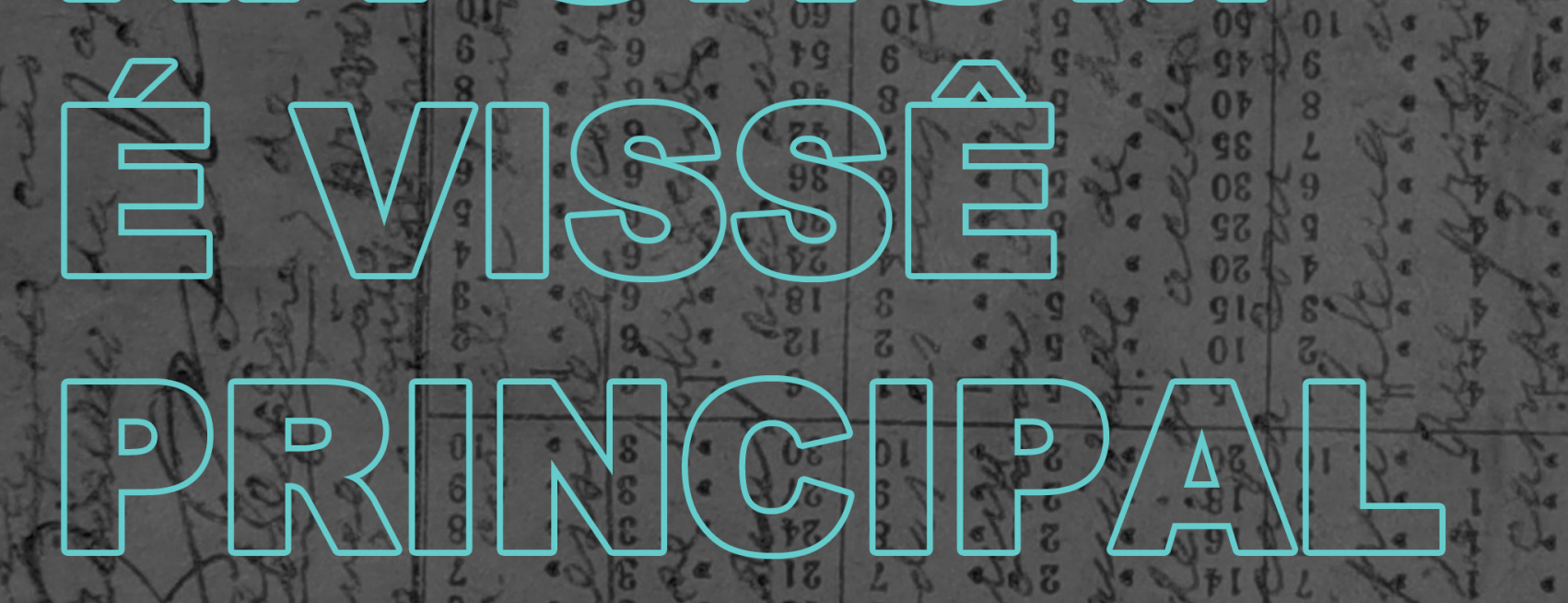

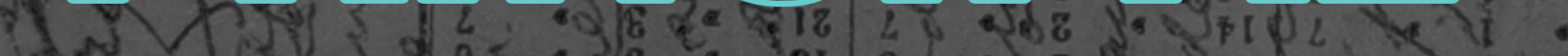

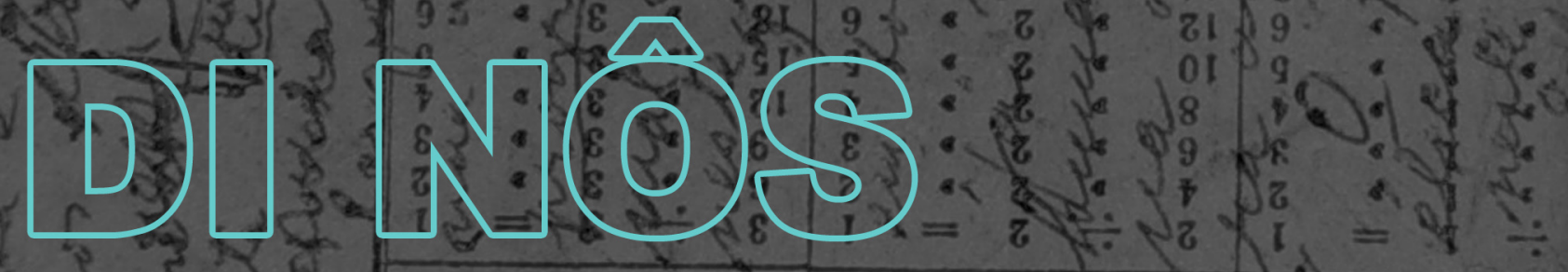

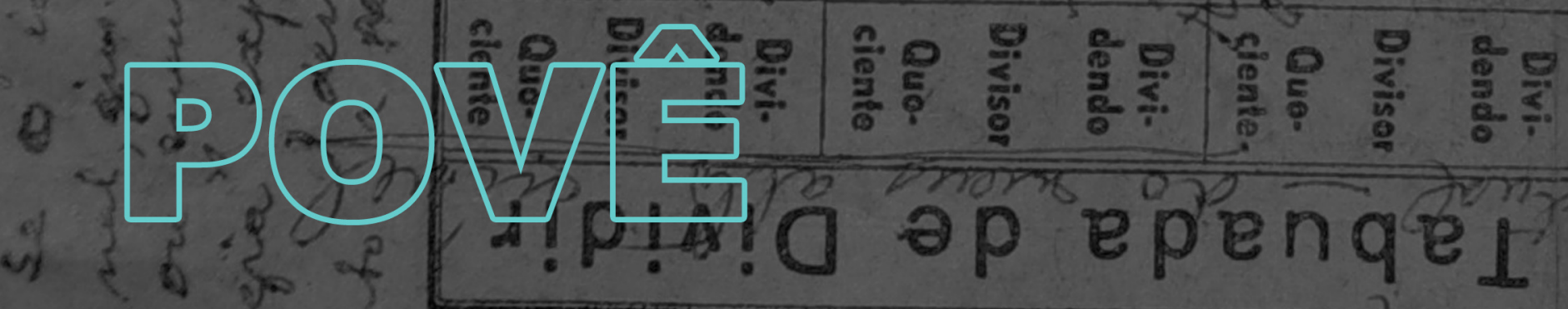

